\title{
Comunicação e educação: em busca dos fundamentos perdidos
}

\author{
Fagner Torres de França* \\ Josineide Silveira de Oliveira**
}

\section{Resumo}

Proliferam-se as tecnologias de comunicação e informação, mas não necessariamente nos entendemos melhor nem somos mais felizes. O presente artigo tem por objetivo retomar os fundamentos da comunicação para uma boa educação. Seremos guiados por dois autores principais. Edgar Morin (1986; 2004; 2001; 2011a) pensa na comunicação como característica fundamental organizadora da vida na Terra. Baitello Júnior $(2012 ; 2014)$ propõe a recuperação do corpo como mídia primordial. Concluímos que uma reforma do pensamento e da educação passa necessariamente por uma reforma da concepção de comunicação.

Palavras-chave: Comunicação; Educação; Edgar Morin

\section{Communication and education: in search of lost foundations}

\section{Abstract}

Communication and information technologies multiply, but we do not necessarily understand each other better and are not happier. The aim of this article is to return to the fundamentals of communication for a good education. We will be guided by two main authors. Edgar Morin (1986, 2004, 2001; 2011a) thinks of communication as a fundamental organizing characteristic of life on Earth. Baitello Júnior $(2012,2014)$ proposes the recovery of the body as a primordial medium. We conclude that a reform of thought and education necessarily involves a reform of the conception of communication.

Key-words: Communication; Education; Edgar Morin

* Doutor em Ciências Sociais pela UFRN. Pesquisador do Grupo de Estudos da Complexidade - GRECOM. fagnertf@yahoo.com.br

** Doutora em Educação; professora do Departamento de Ciências da Religião UERN; do Programa de Pós-Graduação em Educação da UFRN. Vice-coordenadora do Grupo de Estudos da Complexidade/GRECOM/UFRN. josilveira02@gmail.com 


\section{Comunicación y educación: en busca de los fundamentos perdidos}

\section{Resumen}

Se multiplican las tecnologías de comunicación e información, pero no necesariamente nos entendemos mejor ni somos más felices. El presente artículo tiene por objetivo retomar los fundamentos de la comunicación para una buena educación. Seremos guiados por dos autores principales. Edgar Morin (1986; 2004; 2001; 2011a) piensa en la comunicación como característica fundamental organizadora de la vida en la Tierra. Baitello Júnior $(2012$, 2014) propone la recuperación del cuerpo como medios primordiales. Concluimos que una reforma del pensamiento y de la educación pasa necesariamente por una reforma de la concepción de comunicación.

Palabras-clave: Comunicación; Educación; Edgar Morin

\section{Introdução: a teia da incomunicabilidade}

Pesquisa divulgada em 2018 pela Fundação Getúlio Vargas ${ }^{1}$ traz a seguinte notícia: no Brasil, o número de smartphones em circulação já supera o de habitantes. São 220 milhões de aparelhos para aproximadamente 210 milhões de pessoas. A quantidade de computadores vendidos se aproxima dos aparelhos celulares e soma cerca de 175 milhões de unidades. Dados publicizados pelo Facebook também no ano passado ${ }^{2}$ revelam ainda que, dos 2,2 bilhões de usuários mensais desta rede social no mundo, 127 milhões são brasileiros, próximo dos 120 milhões de usuários do WhatsApp no país.

Para além de uma vontade de aquisição dos dispositivos eletrônicos movida por uma política de hiper consumo, facilitada pelos últimos governos antes da recessão econômica que atingiu

LIMA, Mariana. Brasil já tem mais de um smartphone ativo pode habitante, diz estudo da FGV. Disponível em: https://link.estadao.com.br/ noticias/geral,brasil-ja-tem-mais-de-um-smartphone-ativo-por-habitante-diz-estudo-da-fgv,70002275238. Acesso: 17 abri 2019.

2 FERREIRA, Carlos Dias. Facebook chega a 127 milhões de usuários mensais no Brasil. Disponível em: https://canaltech.com.br/redes-sociais/ facebook-chega-a-127-milhoes-de-usuarios-mensais-no-brasil-118358/. Acesso: 17 abri 2019. 
o Brasil há alguns anos, esconde-se nas entrelinhas das estatísticas uma estética, um desejo mais forte e mais humano de estabelecer pontes, corredores, brechas e possibilidades de comunicação, no sentido de criar, manter ou recuperar laços sociais. Em 2016, éramos 116 milhões de pessoas conectadas à internet, ou seja, 64,7\% da população, com a principal finalidade (apontada por 94,6\% dos internautas) de trocar mensagens por aplicativos de bate-papo ${ }^{3}$.

A história mundial não registra época de tamanha quantidade de circulação de informação e produção de sentido, mas não necessariamente nos entendemos melhor. A demanda reprimida por expressão liberada pelas redes sociais parece ter gerado uma cacofonia de informações cujo produto inesperado é a própria incomunicabilidade entre os pretensos sujeitos comunicantes, materializada em uma complicada teia informacional de verdades, erros, ilusões e delírios, difícil de desembaraçar.

É nesta zona obscura onde se alimentam as chamadas fake news, falsas notícias divulgadas massivamente não raro no sentido de conquistar a adesão de multidões para determinados objetivos políticos envolvendo poderosos interesses econômicos. Nos últimos anos, esta prática vem esgarçando as relações sociais ao ponto da ruptura, produzindo perigosas polarizações artificiais e superinfladas com graves consequências para projetos de solidariedade local e global, promovendo a eleição de tiranetes por todo o mundo e comprometendo processos de união regional, vide o chamado Brexit, saída do Reino Unido da União Europeia, e o paulatino desmonte do Mercosul e do BRICS.

Com base neste tema, o presente artigo divide-se em três seções. A primeira parte de uma ideia de comunicação não como epifenômeno do desenvolvimento tecnológico das redes de sociabilidade, mas como necessidade radical da vida e do desenvolvimento

GOMES, Simões Helton. Brasil tem 116 milhões de pessoas conectadas à internet, diz IBGE. Disponível em: https://g1.globo.com/economia/ tecnologia/noticia/brasil-tem-116-milhoes-de-pessoas-conectadas-a-internet-diz-ibge.ghtml. Acesso: 17 abri 2019. 
social. No segundo momento, retornamos a Edgar Morin para pensar uma comunicação de base complexa, componente fundamental da constituição dos sujeitos. Em um terceiro momento, defendemos a relação estreita entre comunicação e formação, a partir de um resgate do corpo (mídia primária), da religação dos saberes e da comunicação como cooperação. Em suma, procuramos pensar a retomada de uma ideia primordial e ampliada de comunicação, com base em Edgar Morin e Norval Baitello Júnior, como aquilo capaz de refazer os laços entre conhecimento e cultura, local e global, indivíduo, sociedade e espécie, educação, formação e cooperação, rumo à constituição do Homo complexus.

\section{Comunicação: uma necessidade radical}

Podemos dizer que a humanidade enfrenta atualmente o desafio de (re)construir a gramática do comum, apostando em um campo no qual, apesar das diferenças, possamos encontrar o eixo que perpassa todos os atravessamentos. Trata-se, portanto, de repensar também a ideia de comunicação. Comunicação é palavra derivada do termo latino communicare, que significa partilhar, tornar comum, estar em relação. A espécie humana constitui soberania no planeta pela capacidade de comunicar, relatar, narrar, transmitir, compartilhar histórias, fábulas, lendas, mitos. É o único animal, lembra Morin (2004), capaz de dizer "era uma vez".

Assim como Morin, Michel Serres assumiu para si a tarefa de narrar a aventura radical do processo de hominização. Era uma vez, diz ele,

Não longe do Istmo de Suez, há mais de 100 mil anos, tempo e locais incertos, uma tribo de africanos [que], atentos e agachados em torno do fogo, acampava. Interrompendo subitamente discussões intermináveis, um punhado deles, excitado, se levantou, decidido a abrir caminho em direção ao sol nascente: para ver, diziam uns, para brincar, diziam outros, para assegurar melhor caça, diziam os mais sábios, para conhecer, talvez (2015, p. 11). 
O historiador israelense Yuval Noah Harari (2017), que se tornou mundialmente famoso por recolocar em pauta a ideia das grandes narrativas do passado, do presente e do futuro, mas também por saber comunicar-se muito bem em seus livros, compreende que nossos irmãos primatas superiores desenvolveram um código vocal capaz de estabelecer arranjos primários de comunicação. Um tipo de grito significa perigo, ameaça, presença de predadores. Ao ouvi-lo, todos os membros do bando primitivo buscam abrigo imediato. Grita-se de outra forma ao encontrar-se comida, ou uma parceria para o acasalamento. Assim acontece com as baleias, os golfinhos, os elefantes, as abelhas. Todas as espécies desenvolveram suas formas mais ou menos sofisticadas de se comunicar com os seus.

$\mathrm{Na}$ medida em que somos seres sociais, estamos a falar da necessidade radical da comunicação para a vida na Terra. No início, diz Harari (2017), constituímos hordas de no máximo 150 indivíduos. Era o número limite de pessoas com quem podíamos travar conhecimento e compartilhar uma vida em comum. A partir daí, em geral ocorria cisão e formava-se novo grupo. Para explicar a coesão da centena e meia de pessoas, Harari recorre à teoria da fofoca. A cooperação social é essencial para nossa sobrevivência e reprodução. Para que isso aconteça, é importante saber, no bando, quem odeia quem, que está dormindo com quem, quem é honesto e quem é trapaceiro, ou seja, em quem podemos ou não confiar. A teoria da fofoca explica muito do comportamento humano ainda hoje, e pode ser utilizada para compreender as tensões, cisões e coalizões humanas até mesmo nos departamentos de universidades.

Embora possamos falar em linguagem das plantas e dos animais, há uma peculiaridade em relação aos humanos. Não apenas alertamos o bando para a presença disso ou daquilo, mas podemos mesmo falar das ausências. Por meio da comunicação, criamos ficções e campos imaginários comuns capazes de envolver e solidarizar (cimentar) os agrupamentos, estreitando laços sociais. Não apenas dizemos: "ali há comida, sombra e água fresca”, mas construímos narrativas fantásticas, envolventes e sedutoras sobre 
eldorados, jardins e paraísos nos quais tudo existe em abundância e pessoas e animais viverão eternamente em plena harmonia. Não é essa um pouco da nossa ideia atual de Nação, uma comunidade imaginada que compartilha da mesma história, das mesmas crenças, da mesma origem e do mesmo destino?

A característica verdadeiramente única de nossa linguagem, diz Harari, é a capacidade de transmitir informações sobre coisas que não existem. A ficção

nos permitiu não só imaginar coisas como fazer isso coletivamente. Podemos tecer mitos partilhados, tais como a história bíblica da criação, os mitos do Tempo do Sonho dos aborígenes australianos e os mitos nacionalistas dos Estados modernos. Tais mitos dão aos sapiens a capacidade sem precedentes de cooperar de modo versátil em grande número (2017, p. 33).

À nossa capacidade de fazer a comunicação delirar, Harari (2017) chama de Revolução Cognitiva. Este é o segredo de termos saído de uma comunidade "natural" de um bando com 150 indivíduos e fundado cidades e impérios com milhões de pessoas mergulhadas em um mesmo caldo imaginário. Acreditamos na ficção jurídica, na ficção religiosa, na ficção do dinheiro, na ficção da democracia e da política. Em uma palavra, o mundo é a história de ficções mais ou menos bem sucedidas questionadas a partir de algumas brechas e lacunas em suas fissuras narrativas. O argumento é uma ampliação sofisticada da máxima pronunciada há algumas décadas por Abelardo Barbosa: "quem não se comunica se trumbica".

Mas o quanto de conhecimento não perdemos com a proliferação da informação? Byung-Chul Han (2017), herdeiro tanto de Jean Baudrillard quanto da Teoria Crítica da Escola da Frankfurt, alerta para o fato de que vivemos hoje em uma sociedade da transparência. O imperativo da sociedade da transparência é eliminar toda e qualquer negatividade da comunicação, no sentido de fazê-la deslizar sem qualquer atrito e o mais rapidamente possível. Negatividade, aqui, significa crítica, alteridade, resistência, espaço, distância. É o 
tempo lento da compreensão, da reflexão, do estranhamento e do entranhamento. Hoje em dia, é muito comum encontrar professores universitários queixando-se do fato de que os alunos não leem, se leem, não entendem, quando entendem, entendem rápido demais, e são capazes de descartar a herança profunda de grandes pensadores depois de uma breve leitura axilar de 15 minutos.

Uma sociedade assim pode ser chamada também de positiva (HAN, 2017). A negatividade paralisa a comunicação em favor da explosão de informações. Estas devem circular sem fricção, livre de perturbações, tornando-se assim a própria comunicação. $\mathrm{O}$ meio não é mais a mensagem. A mensagem é a própria mensagem. Em um mundo assim, diz Han, transformado em máquina, somos apenas elemento funcional respondendo adequadamente aos estímulos informacionais sem lhes opor resistência. A transparência responde, na verdade, a um vaz̧io de sentido. A massa de informação e comunicação a qual estamos expostos responde a um horror vacui (p. 36).

As redes sociais da internet são um exemplo disso. Em muitos casos, lá estamos não para estabelecer comunicação, mas para trocar mensagens. Estas mensagens, independente de seu conteúdo, são a própria comunicação. Não trocar mensagens é retirar-se do fluxo informacional e condenar-se ao esquecimento. Para agilizar o processo, substituímos as cansativas e ultrapassadas palavras por carinhas tristes ou alegres, likes e corações. A angústia da demora na resposta a uma interpelação por meio de aplicativos como o WhatsApp é a própria materialização do horror ao vazio.

Nesse quadro, a arte, a palavra e o pensamento são, hoje, o último reduto onde se esconde a negatividade. Daí o ataque dos governos conservadores aos artistas, escritores e intelectuais. Fazemos política por meio de memes. Nazareth Tedesco decide eleições. É a memetização do mundo. $\mathrm{E}$ assim vamos produzindo um processo de "desnarrativização" da história. A sociedade da transparência, da positividade e da informação produz um apagamento da comunicação e da memória em benefício da informação ágil e atualizada, sem entraves. 
Resgatar uma ideia complexa de comunicação (de campo comum) é hoje tarefa fundamental para a sociedade planetária, principalmente por causa da multiplicidade de mediações apresentada pela sociedade tecnológica. Morin é um dos autores que, sem dúvida, recuperam a ideia de comunicação com mais radicalidade. $\mathrm{O}$ verbo recuperar pode remeter, em um primeiro momento, a uma ideia conservadora, de retorno, retomada ou conservação. Mas aponta também para o que há de mais radical em nós, ou seja, a própria ideia de ação comum, cooperação, criação de vínculos.

A comunicação é um sistema básico de vinculação. A verdadeira comunicação lança pontes ao invés de interditar os caminhos. Trata-se, na verdade, de conservar revolucionando e revolucionar conservando. $\mathrm{Na}$ leitura que ora propomos, a questão da comunicação aparece como um dos temas fundamentais para se compreender a obra de Edgar Morin. A comunicação em Morin, acreditamos, guarda relação direta com a reforma do pensamento e da vida política devido à importância que o pensador francês atribui à democracia cognitiva, principalmente no âmbito das sociedades modernas hipercomplexas.

\section{Recuperando a comunicação}

Cultura de massas no século XX, vol. 1 - Neurose (2011), lançado em 1962, é até hoje um dos textos de Edgar Morin mais vendidos e conhecidos, tendo sido reabilitado nos últimos anos e aplicado em diversos cursos de comunicação e sociologia do mundo. Esta obra, voltada para o fenômeno da comunicação e da cultura de massas, pode ser lida, em outro nível, como um livro de antropologia fundamental. Nele Morin já anuncia o nascimento do que chama de cosmopitecos, uma espécie de sujeito universal. E quem é esse sujeito universal? É o sujeito puro e simples, isto é, o grau de humanidade comum a todos os seres humanos? Sim e não.

Sim, no sentido de que se trata do homem imaginário, que em toda parte responde às imagens pela identificação ou projeção. Sim, se se trata do homem-criança que se encontra em toda pessoa, curioso, gostando do 
divertimento, do mito, do conto. Sim, se se trata do homem que em toda a parte dispõe de um tronco comum de razão perceptiva, de possibilidades de decifração, de inteligência (p. 54).

Trata-se de um anthropos universal. Essa ideia esta na raiz da noção de unidade antropológica, que será desenvolvida em praticamente todos os seus livros. Tal retorno aos fundamentos da comunicação como estando na base de um sujeito universal é o fio que costura a trindade indivíduo, sociedade e espécie. A teoria da informação está no centro do pensamento moriniano. Por meio dela é possível tornar ainda mais profunda a noção de comunicação, já que a informação seria sua unidade mínima. A circulação informacional garante a organização da vida internamente e, de forma mais ampla, na relação de troca com o meio, garantindo assim sua auto-eco-organização. Nesse sentido, a manutenção, organização, desorganização, degeneração, degradação, regeneração ou reorganização de um sistema vivo depende, portanto, dos elementos informacionais que nele circulam ${ }^{4}$.

Em nível político e social as repercussões desta elaboração tornam-se mais claras. Uma democracia política, para ser efetiva, deve vir acompanhada de uma democracia cognitiva e de uma inadiável reforma do pensamento. A impressão geral é a de que quanto mais se desenvolvem as tecnologias da informação e da comunicação mais difícil e truculenta se torna a própria comunicação, assim como o desenvolvimento dos meios de comunicação gera uma cacofonia quase inextricável de informações. É o que Morin chama de nuvens de subinformação, psendoinformação e superinformação, materializadas, por exemplo, nas fake news.

Podemos dispor de uma massa assombrosa de informação e mesmo assim não constituir conhecimento algum. Um computador armazena milhões de dados e estatísticas e mesmo assim não

Um desdobramento desta discussão sobre a biologia da informação e da comunicação em Edgar Morin pode ser encontrado em: FRANÇA, Fagner Torres de; ALMEIDA; Maria da Conceição de. Sociologia do presente, ciências da cultura, complexidade. Natal: EDUFRN, 2019. 
produz conhecimento. A produção de conhecimento exige seleção, articulação e tratamento de informações. Conhecer significa dar forma e sentido a essa matéria bruta, capacidade de situar a informação em determinado contexto, construindo aquilo que Morin chama de conhecimento pertinente. O contrário disso é a própria barbárie do pensamento.

Um pensamento bárbaro, incapaz de estabelecer pontes, conexões e comunicações com conhecimentos diversos produz barbáries civilizacionais, por não conceber o mundo como uma teia tecida de múltiplos conhecimentos, por vezes complementares, concorrentes e antagônicos. Mas é justamente esse "calor cultural" (MORIN, 2011a), essa pluralidade de vozes, desejos e interesses discordantes e consonantes em um ambiente de liberdade de expressão que possibilitou o nascimento da democracia e permitiu sua constante regeneração - tendo em mente o caráter inacabado de toda democracia.

Para Morin (1986), é urgente "aspirar a uma ação política a menos mutilante possivel' (p. 121, grifo do autor). E isso está na base da nossa própria estrutura de pensamento, que comanda simultaneamente nossas visões de mundo, da vida, da sociedade e da política. A estrutura de pensamento disjuntiva/redutora traz em si a mutilação. Já o pensamento complexo é "capaz de associar o que está separado e conceber a multidimensionalidade de toda realidade antropossocial" (p. 122). É um tipo de pensamento que reconhece e estende uma ponte em direção ao outro, ao invés de recusar ou desconhecer sua existência. Falamos de um pensamento que se faz apenas enquanto produz comunicação.

Quanto mais complexo um sistema de ideias, mais receptível se torna à comunicação (ou, poderíamos dizer, ao campo da argumentação racional), mais aberto ao ruído, à desordem, ao acontecimento, aos possíveis elementos disruptivos. Um sistema de ideias pode ser aberto à informação, receptivo às trocas provenientes de outros sistemas de ideias. Nesse caso, estamos diante de uma teoria. Quando permanece fechado ao questionamento, trabalhando unicamente a partir de sua lógica interna, um sistema de ideias é 
identificado com uma doutrina. Neste ponto, diz Morin, chegamos ao problema capital: "a relação repulsiva e potencialmente desintegradora entre informação e ideologia política" (1986, p. 45, grifo do autor). Uma informação forte num ponto fraco da ideologia é capaz de abrir a racionalização para a racionalidade e, no limite, dinamitar todo um sistema de ideias.

Uma democracia cognitiva deve sempre observar a diversidade/concorrência das fontes de informação. Nesse sentido, a superinformação é sempre melhor do que a subinformação. $\mathrm{Na}$ incapacidade de verificar empiricamente um fato, como é o caso da grande maioria das informações que recebemos diariamente, é ao confronto das diferentes narrativas que poderemos recorrer para elaborar uma opinião. Precisamos dos sistemas de ideias para organizar as informações transmitidas pelo mundo. Mas a ideologia não pode calar o fenômeno, que deve, sempre que possível, ser posto à prova da verificação lógica e empírica.

Em suma, torna-se cada vez mais difícil organizar a informação como conhecimento e comunicação. A proliferação das tecnologias da informação e comunicação parece não ter estendido pontes, mas, pelo contrário, cavado fossos intransponíveis. As polarizações políticas reproduzem-se em todo o mundo: Brasil, América Latina, EUA, Europa. Fechados em bolhas ideológicas, fora do alcance do ruído, da desordem, da diferença, da crítica, da reflexão, da alteridade, enfim, longe de toda negatividade, acabamos por implodir o centro político. A questão que se coloca é a de saber qual o destino de uma sociedade na qual a comunicação encontra-se interditada, se entendermos comunicação também como o que é da ordem do encontro, do acontecimento, da abertura para o mistério, o imprevisível, o imponderável, aquilo que pode desorganizar nosso conhecimento prévio sobre o mundo a fim de dar lugar a uma outra organização do pensamento.

Os fundamentalismos não são apenas religiosos ou políticos. O pensamento cotidiano abriga com freqüência seus fundamentalismos e fanatismos. Acontece nos estádios de futebol, nas dis- 
putas políticas, nos shows musicais, na defesa do nosso território contra inimigos imaginários, internos e externos. Nossos sistemas de ideias, marcados ainda muito cedo na infância por experiências e imprintings culturais, sociais, econômicos, trabalham de modo a justificar nossas ações e ideologias, evitando qualquer dissonância cognitiva. Rejeitamos as ideias que entram em conflito com nossas crenças, enquanto aceitamos, muitas vezes acriticamente, qualquer coisa que nos justifique e absolva.

Quando não está sujeito à (auto)crítica, o pensamento desanda em fanatismos, ilusões, erros, barbáries e fascismos. Defendemos com unhas e dentes ideias que nem mesmo sabemos de onde partiram, mas mesmo assim as incorporamos aos nossos esquemas de interpretação do mundo; ideias que não resistiriam a 15 minutos sob a luz do sol. Nesse contexto, o papel do intelectual hoje deve ser o de repensar os fundamentos da comunicação, reconstruir as pontes, borrar as fronteiras do conhecimento, desfragmentar os saberes, desarmar os espíritos e fazer comunicar os pólos em conflito. Não há outra escolha: pólos incomunicáveis não fazem emergir o caminho do meio.

\section{Comunicação e formação: corpo, conhecimento, cooperação}

Norval Baitello Jr., professor de Teoria da Mídia e da Cultura na PUC/SP é um dos mais renomados teóricos da imagem no Brasil e um dos principais estudiosos e comentadores da obra do filósofo tcheco-brasileiro Vilém Flusser. Em O pensamento sentado (2012), Baitello Jr. faz referência a uma palestra proferida por Flusser em 1990 na Alemanha, intitulada "reflexões nômades", na qual propõe uma periodização da história da humanidade em três etapas.

Em sua história, o ser humano teria sobrevivido a três grandes catástrofes. A primeira delas seria a hominização, o abandono das copas das árvores e consequentemente o bipedismo. Daí surge o sujeito nômade que faz da atividade de deslocar-se uma forma de conhecer e reunir experiências sobre o mundo. A 
segunda catástrofe é denominada de civilização, ou seja, a sedentarização. Surge o ser acumulador e cioso de suas posses, mas também a escrita e o sistemas lógico, numérico e de cálculos, que permitiram o desenvolvimento da ciência e da técnica. Vivemos hoje a terceira grande catástrofe, ainda sem nome, "na qual a proteção e o aconchego das habitações deixaram de existir, pois nossas casas estão perfuradas por todos os lados, tornaram-se permeáveis aos 'furacões da mídia”" (BAITELLO JR., 2012, p. 27-28, grifo nosso). Perfuradas pela TV a cabo, a internet, a parabólica, o som ao redor, o rádio, as redes sociais, em suma, pelos “deuses do vento" . Vivemos um misto de nomadismo e sedentarismo, mobilismo e imobilismo, atividade e passividade.

As habitações são lugares de aconchego e proteção, mas também espaços inóspitos, invadidos por uma diversidade crescente de estímulos renovados. As imagens estão sempre convidando a partir, conhecer países distantes, viver novas experiências, enfrentar desafios improváveis, mas o fazemos, na maioria dos casos, sem sair do sofá. Esta é uma das grandes contradições trazidas pela terceira catástrofe.

Baitello Jr. (idem) convida para pensarmos o lugar do sujeito numa sociedade na qual as imagens e a comunicação de massas assumem um lugar cada dia mais relevante nas mediações do sujeito com o mundo, com os outros e com ele próprio. Nesse contexto, no plano da educação, formar significa também reformar as relações humanas, reencontrar o lugar da materialidade de um corpo capaz de produzir bons afetos. Trata-se, portanto, de resgatar a potência comunicacional do corpo.

Claude Lévi-Strauss foi ao Japão cinco vezes entre 1977 e 1988. De suas andanças, observações e percepções sobre o império do sol nascente, o antropólogo francês faz o seguinte destaque:

\footnotetext{
5 "Crenças pagãs afirmavam ser o sopro do vento o fecundador de determinados animais. Em numerosas mitologias essa imagem do sopro que confere vida se repete, já então se referindo ao homem e a todas as criaturas" (BAITELLO JR., 2012, p. 31).
} 
Entre a fidelidade ao passado e as transformações induzidas pela ciência e pelas técnicas, o Japão, talvez a única de todas as nações, soube até agora encontrar um equilíbrio. Talvez o deva primeiro ao fato de que entrou nos tempos modernos por meio de uma restauração e não como, por exemplo, a França, por meio de uma Revolução. Seus valores tradicionais foram assim protegidos de uma derrocada. Mas também o deve a uma população que por muito tempo ficou disponível, abrigada do espírito crítico e do espirito de sistema cujos excessos contraditórios minaram a civilização ocidental. Hoje ainda, o visitante estrangeiro admira esse zelo de cada um em bem cumprir seu oficio, essa boa vontade alegre que, comparados ao clima social e moral dos países de onde ele vem, lhe parecem virtudes capitais do povo japonês. Que possa esta manter por muito tempo esse precioso equilíbrio entre tradições do passado e inovações do presente; não só para seu próprio bem, pois a humanidade inteira encontra aqui um exemplo em que meditar (2012, p. 101, grifo nosso).

A partir da década de 1980, um fenômeno minoritário, talvez ainda não detectado por Lévi-Strauss, começa a ganhar corpo, sob o assédio do "espírito crítico e do espírito de sistema" ocidentais dos quais os japoneses estavam abrigados até então. Há anos o Japão vem registrando o crescimento do chamado kodokushi, ou "morte solitária". O kodokushi aponta possivelmente para o problema do esgarçamento das relações sociais e da tradição de "boa vontade alegre" dos nipônicos. Um em cada cinco japoneses morre sem que ninguém reclame seu corpo por dias ou, em casos extremos, até meses. Geralmente, autoridades são alertadas somente quando o corpo morto esquecido em vida passa a incomodar aos demais corpos vivos devido à dinâmica biológica da decomposição da matéria.

No Brasil, a indiferença ao corpo outro é bastante mais acintosa, passando pelo desejo de eliminação física voluntária da alteridade. Apenas em 2018, o país registrou o número assustador de 51.589 mortes violentas, 24,7 mortos a cada 100 mil habitantes $^{7}$,

6 Disponível em: https://www.jornalciencia.com/kodokushi-ou-morte-solitaria-um-fenomeno-sinistro-que-vem-crescendo-no-japao/. Acesso em 27 abri 2019.

7 Disponível em: https://g1.globo.com/monitor-da-violencia/noticia/ 2019/02/27/numero-de-mortes-violentas-cai-mais-de-10-no-brasil-em-2018.ghtml. Acesso em 27 Abri 2019. 
número 13\% menor que 2017! Não o deixar(-se) morrer Japonês, mas o fazer morrer e deixar viver. Tal processo de exterminação violenta elimina a própria possibilidade do corpo enquanto possibilidade de comunicação.

Baitello Jr. (2014) identifica no nascimento um ato inaugural de toda a comunicação humana. Consequentemente, a morte é o fim da comunicação. "Todo processo comunicativo tem suas raízes em uma demarcação espacial chamada corpo. O que se denomina comunicação nada mais é que a ponte entre dois espaços distintos" (p. 94). Baitello classifica o corpo comunicacional a partir da ideia de mídia primária, formulada inicialmente por Harry Pross. Significa que tudo começa e termina no corpo, com suas intermináveis possibilidades de produção de linguagens e sentidos: os sons, a fala, os movimentos, o sentar, o andar, os odores e rubores, a palidez, as rugas e cicatrizes, os sorrisos e as lágrimas.

Em tempos de tecnologias e apagamentos de memórias e materialidades, essa verdade, diz Baitello Jr. (idem), precisa ser retomada, ou seja, a do corpo como instância fundante para o processo comunicativo como um todo, portanto instaurador de vínculos sociais, pois

É com ele que se conquista a dimensão da horizontalidade e as relações solidárias de igualdade. É com o corpo, gerando vínculos, que alguém se apropria de seu próprio espaço e de seu próprio tempo de vida, compartindo-os com outros sujeitos. Mas é também aí, no estabelecimento de vínculos, materiais ou simbólicos, que inicia a apropriação do espaço e do tempo de vida de outros (p. 96).

Comunicar é também lançar/construir pontes. As pontes possibilitam passagens, aberturas, mas principalmente encontros. Numa perspectiva ampliada, o filósofo francês Michel Serres (1995) convoca todos os anjos, em suas múltiplas encarnações, no sentido de multiplicar as comunicações. Nas tradições monoteístas judaica, cristã e muçulmana - os anjos são mensageiros de Deus, transitando entre o céu e a terra, capazes de percorrer o espaço na 
velocidade do pensamento. Aviões, jornalistas, escritores, intelectuais, professores, artistas, precisamos todos assumir a figura do bom mensageiro. Os miseráveis que nos interpelam nos semáforos, bares e esquinas são os mensageiros da miséria, o Arcanjo, de arqué, elemento do início, do meio e do fim, a nos lembrar que da miséria viremos e a ela voltaremos (idem; ibidem).

Os anjos não comunicam necessariamente corpos, mas pensamentos, conhecimentos, sentimentos. Ao buscar comunicar conhecimentos dispersos, muitos deles tornados hoje em dia incomunicáveis, constituindo um apartheid cultural, como identifica Charles Percy Snow (1993) em relação às ciências exatas e às humanidades ${ }^{8}$, Edgar Morin faz o papel de anjo comunicador indispensável para a sociedade contemporânea. Pensa na comunicação como aquilo capaz de restabelecer o comum. Complexidade nada mais é que a possibilidade de sairmos da fragmentação e do isolamento (social, intelectual, afetivo) para tecermos coisas em conjunto. É um estilo de pensamento passível de estabelecer relações entre saberes aparentemente distantes e distintos.

Uma boa formação exige que tenhamos acesso ao repertório mais fundamental das obras de arte, da literatura, do cinema e do pensamento capazes de nos ensinar em profundidade os dilemas da condição humana. Livros, filmes, música, quadros, poemas, esculturas, conceitos, teorias e sistemas filosóficos são conexões construídas com a finalidade de nos projetar para o outro (e para si, levando em consideração que o outro também nos constitui). São, simultaneamente, escolas da língua, da qualidade poética e estética da vida, escolas da descoberta de si, escolas da complexidade e da compreensão humanas. Recorrendo aos clássicos da literatura mundial, afirma Morin:

8 Para Snow, se um discípulo das humanidades repreende arrogantemente um adepto das ciências exatas por não ter lido uma única peça de Shakespeare, este acusa aquele de não conhecer sequer as Leis de Newton. Corresponde ao mesmo pecado. $\mathrm{O}$ chiste dá uma dimensão aproximada da fratura que nos separa. E não deixa de ser verdadeiro ainda hoje. 
É no romance ou no filme que reconhecemos os momentos de verdade do amor, o tormento das almas dilaceradas, e descobrimos as profundas instabilidades da identidade, como em Dostoievsky; a multiplicidade interior de uma mesma pessoa, em Proust; assim como, em Pai Goriot e Guerra e Paz, a transformação dos seres, confrontados com o destino social ou histórico, levados pela torrente de acontecimentos que podemos nos tornar heróis, mártires, covardes, carrascos.

\section{E acrescenta:}

É no romance, no teatro, no filme, que percebemos que Homo sapiens é, ao mesmo tempo, indissoluvelmente, Homo demens. É no romance, no filme, no poema, que a existência revela sua miséria e sua grandeza trágica, com o risco de fracasso, de erro, de loucura. É na morte de nossos heróis que temos nossas primeiras experiências de morte. É, pois, na literatura que o ensino sobre a condição humana pode adquirir forma vívida e ativa, para esclarecer cada um sobre sua própria vida (2004, p. 49).

Em suma, a autoconsciência se manifesta no contexto da comunicação com o outro. Grandes artistas e intelectuais são pessoas capazes de estabelecer comunicações originais com o mundo. Assim fizeram Antonin Artaud, Arthur Rimbaud, Nietzsche, Spinoza, Edgar Morin. Atuam, portanto, como forças de conjunção. Ativam a compreensão, a cooperação e a convivialidade, degradadas pela aceleração, individualização, fragmentação, anonimização e burocratização da vida cotidiana.

O sociólogo estadunidense Richard Sennett (2012) é um dos que pensam sobre a necessidade de resgatarmos a cooperação como habilidade social capaz de articular a diferença em torno de um objetivo comum. Cooperação como habilidade "requer a capacidade de entender e mostrar-se receptivo ao outro para agir em conjunto" (p. 10), "uma troca em que as partes se beneficiam" (p. 15). A clássica cisão ocidental mente/corpo fez com que nos tornássemos incapazes de religar até mesmo as coisas mais próximas, como a mente e a mão.

Sennett pensa em uma política da cooperação principalmente por meio da ideia de trabalho, com ênfase no Homo faber. Em 
Morin, a cooperação demanda uma articulação complexa entre saberes e fazeres capaz de engendrar um Homo complexus, que absorve e ao mesmo tempo ultrapassa o Homo faber, apontando para uma política de solidarização, donde a ideia de unitas-multiplex, ou seja, a unidade da multiplicidade e da diversidade humanas. Apenas a tomada de consciência para a questão da solidariedade humana pode desviar o planeta dos rumos do abismo. Isso significa também pensar na solidariedade das questões que nos atravessam a todos enquanto comunidade planetária: a democracia política, a financeirização da economia, os fenômenos migratórios, as guerras (sempre virtualmente nucleares), mas sobretudo o problema ecológico, com potencial de acelerar o fim da espécie humana, desconhecendo as diferenças, distinções e hierarquias sociais.

Em suma, para tudo isto está posto o desafio da comunicação: recuperar o terreno possível do diálogo, evitar divisões políticas, econômicas, sociais e morais em excesso, furar as bulhas ideológicas que cegam e matam o outro (simbólica e fisicamente), fazer comunicar valores e sistemas de crenças que não encontram mais gramática comum de expressão, resgatar os espaços do corpo e a visibilidade dos corpos no espaço, religar áreas de conhecimento, lançar pontes entre os (des)vãos da hiperespecialização do saber, reaver a herança humanística comum das artes, do cinema, da literatura e do pensamento, reforçar a necessidade da solidarização mundial como corpo político coeso disposto a encontrar soluções conjuntas para problemas globais, comunicar a unidade com a diversidade humana, possibilitar o parto difícil do já indispensável Homo complexus.

\section{Referências}

BAITELLO JR., Norval. O pensamento sentado. Sobre glúteos, cadeiras e imagens. São Paulo: Unisinos, 2012.

BAITELLO JR., Norval. A era da iconofagia. Reflexões sobre a imagem, comunicação, mídia e cultura. São Paulo: Paulus, 2014.

FERREIRA, Carlos Dias. Facebook chega a 127 milhões de usuários mensais no Brasil. Disponível em: https:/ / canaltech.com.br/redes-sociais/facebook-chega-a-127-milhoes-de-usuarios-mensais-no-brasil-118358/. Acesso: 17 abri 2019. 
GOMES, Simões Helton. Brasil tem 116 milhões de pessoas conectadas à internet, diz IBGE. Disponível em: https://g1.globo.com/economia/tecnologia/ noticia/brasil-tem-116-milhoes-de-pessoas-conectadas-a-internet-diz-ibge.ghtml. Acesso: 17 abri 2019.

LIMA, Mariana. Brasil já tem mais de um smartphone ativo pode habitante, diz estudo da FGV. Disponível em: https://link.estadao.com.br/noticias/ geral,brasil-ja-tem-mais-de-um-smartphone-ativo-por-habitante-diz-estudo-da-fgv,70002275238. Acesso: 17 abri 2019.

HAN, Byung-Chul. A sociedade da transparência. Trad. Ênio Paulo Giachini. Petrópolis, RJ: Vozes, 2017.

HARARI, Yuval Noah. Sapiens. Uma breve história da humanidade. Trad. Janaína Marcantônio. 26a Ed. Porto Alegre, RS: L\&PM, 2017.

LÉVI-STRAUSS, Claude. A outra face da lua. Escritos sobre o Japão. Trad. Rose Freire d'Aguiar. São Paulo: Cia. das Letras, 2012.

MORIN, Edgar. Para sair do século XX. Tradução Vera Azambuja Harvey. Rio de Janeiro: Nova Fronteira, 1986.

MORIN, Edgar. A cabeça bem-feita. Repensar a reforma, reformar o pensamento. Trad. Eloá Jacobina. 9a Ed. Rio de Janeiro: Bertrand Brasil, 2004.

MORIN, Edgar. Cultura de massas no século XX - Neurose.Vol. 1.Tradução de Agenor Soares Santos. RJ: Forense, 2011.

MORIN, Edgar. O método 4: as ideias - habitat, vida, costumes, organização. Tradução Juremir Machado da Silva. 6ª Ed. Porto Alegre: Sulina, 2011a.

SENNETT, Richard. Juntos. Os rituais, os prazeres e a política da cooperação. Trad. Clóvis Marques. Rio de Janeiro: Record, 2012.

SERRES, Michel. A lenda dos anjos. Trad. Rosângela Vasconcellos Tibúrcio. São Paulo: Editora Aleph, 1995.

SERRES, Michel. Narrativas do humanismo. Trad. Caio Meira. $1^{\text {a }}$ Ed. Rio de Janeiro: Bertrand Brasil, 2015.

SNOW, Charles Percy. As duas culturas e um segundo olhar. Trad. por Renato Rezende Neto. São Paulo: Editora da Universidade de São Paulo, 1993. 